\title{
Is North America the best place for PCNL in obese patients?
}

\author{
Darren Beiko, MD, MBA, FRCSC; ${ }^{*}$ Janet van Vlymen, MD, FRCPC ${ }^{+}$
}

`Department of Urology, Queen's University, Kingston General Hospital, Kingston, ON; †Department of Anesthesiology and Perioperative Medicine, Queen's University, Kingston General Hospital, Kingston, ON

Cite as: Can Urol Assoc J 2014;8(1-2):22-3. http://dx.doi.org/10.5489/cuaj.1676

Published online February 10, 2014.

$\mathrm{T}$ he article by Alyami and colleagues titled "Impact of body mass index on clinical outcomes associated with percutaneous nephrolithotomy"1 found no statistically significant difference in percutaneous nephrolithotomy (PCNL) outcomes across various body mass indices (BMI) in 114 patients. These findings from their retrospective chart review are not new; Averch's group and Lotan's group have previously shown no impact of BMI on PCNL outcomes in 234 and 150 patients, respectively. ${ }^{2,3}$ It is difficult to draw strong conclusions from these 3 studies, especially given that very small numbers of patients were studied in some of the BMI categories. On the other hand, the Clinical Research Office of the Endourological Society (CROES) Percutaneous Nephrolithotomy Global Study that was published last year showed-in an impressive 3,709 patients-that obesity did indeed have a negative impact on operative times, stonefree rates and re-intervention rates. ${ }^{4}$ Given the contradictory results between the 3 former smaller North American studies and the latter large global trial, and allowing for the acknowledged flaws in the study design of all 4 studies, can one reasonably conclude that North America is the best place for PCNL in obese patients? We think not.

We generally agree with the authors' findings, but in our experience here at Queen's University, one particular PCNL outcome is different in obese patients - length of hospital stay. The reason is simple: we are one of two Canadian centres with published series on truly outpatient PCNL, ,,6 and most obese patients are not candidates for hospital discharge mere hours post-PCNL. Although a number of studies have shown there is no increase in unplanned admissions after outpatient surgery in obese patients, the incidence of obstructive sleep apnea (OSA) among these patients is over $70 \% .^{7}$ Recent guidelines from the Society for Ambulatory Anesthesia (SAMBA) recommend that patients with treated
OSA who have stable concomitant disease are suitable for outpatient surgery. ${ }^{8}$ However, patients with untreated or suspected OSA that require opioid analgesics postoperatively are not good candidates for ambulatory surgical procedures. The requirement for overnight admission for oximetry monitoring in these patients results in an increased length of stay unrelated to the surgical procedure.

Given the fact that obesity is more prevalent in North America than other parts of the world ${ }^{9}$ perhaps it is indeed the best place for obese patients to undergo PCNL. After all, North America is where urologists obtain a greater experience performing PCNL in obese patients. Could this partly explain Alyami's encouraging PCNL results in obese patients?

Competing interests: Dr. Beiko and Dr. van Vlymen declare no competing financial or personal interests.

\section{References}

1. Alyami FA, Skinner TAA, Norman RW. Impact of body mass index on clinical outcomes associated with percutaneous nephrolithotomy. Can Urol Assoc J 2013;7:E197-201. http://dx.doi.org/10.5489/ cuaj.11229. Epub 2012 May 15.

2. Tomaszewski JJ, Smaldone MC, Schuster T, et al. Outcomes of percutaneous nephrolithotomy stratified by body mass index. J Endourol 2010;24:547-50. http://dx.doi.org/10.1089/end.2009.0431

3. Bagrodia A, Gupta A, Raman JD, et al. Impact of body mass index on cost and clinical outcomes after percutaneous nephrostolithotomy. Urology 2008;72:756-60. http://dx.doi.org/10.1016/i.urology.2008.06.054

4. Fuller A, Razvi H, Denstedt ID, et al.; CROES PCNL Study Group. The CROES percutaneous nephrolithotomy global study: The influence of body mass index on outcome. J Urol 2012;188:138-44. http://dx.doi. org/10.1016/i.juro.2012.03.013

5. Beiko D, Lee L. Outpatient tubeless percutaneous nephrolithotomy: The initial case series. Can Urol Assoc J 2010;4:E86-90.

6. Shahrour W, Andonian S. Ambulatory percutaneous nephrolithotomy: Initial series. Urology 2010;76:128892. http://dx.doi.org/10.1016/i.urology.2010.08.001

7. Lopez PP, Stefan B, Schulman Cl, et al. Prevalence of sleep apnea in morbidly obese patients who presented for weight loss surgery evaluation: More evidence for routine screening for obstructive sleep apnea before weight loss surgery. Am Surg 2008;74:834-8.

8. Joshi GP, Ankichetty SP, Gan TJ, et al. Society for Ambulatory Anesthesia Consensus Statement on Preoperative Selection of Adult Patients Scheduled for Ambulatory Surgery. Anesth Analg 2012;1 15:10608. http://dx.doi.org/10.1213/ANE.0b013e318269cfd7 
9. Su D, Esqueda OA, Li L, et al. Income inequality and obesity prevalence among OECD countries. J Biosoc Sci 2012;44:417-32. http://dx.doi.org/10.1017/S002193201100071X

Correspondence: Dr. Darren Beiko, Department of Urology, Queen's University, Kingston General Hospital, 76 Stuart St., Kingston, ON K7L 2V7; fax: 613-545-1970; beiko@queensu.ca

\section{Continuing medical education: The perspective of quality improvement}

\author{
Kieran Walsh, FRCPI \\ BMJ Learning, BMJ Publishing Group, London, UK
}

Cite as: Can Urol Assoc J 2014;8(1-2):23. http://dx.doi.org/10.5489/cuaj.1767

Published online February 10, 2014.

A hmed and colleagues are to be congratulated for their scholarly review of the effectiveness of continuing medical education (CME) for the purposes of specialist recertification. ${ }^{1}$ They are correct to point out the dangers of healthcare professionals viewing CME as a method of accumulating credits for its own sake - rather than as a means of improving their practice. This is likely to be particularly at issue in the case of specialist CME where an individual tertiary care specialist may gather the requisite number of credits, but still not do much CME that relates directly to their clinical practice and thus that will improve their clinical practice. In any case, education is not like a drug - it is difficult to definitively prove its "effectiveness" by means of traditional quantitative research trials. It is likely that another perspective is called for.

That perspective may best come from the paradigm of improvement science rather than that of education. It may be better for specialists to measure key outcomes of their practice at baseline, institute clinical quality improvement measures and continually re-measure and measure at the end of a fixed period. At the end they might evaluate the improvement project and see what they have learned. Improvement may thus result in learning, rather than learning resulting in improvement. The key advantage of this approach is that it would result in a project tailored to the individual clinician's need - regardless of their degree of specialization.

Finally the authors are right to draw their review to a close with research questions for the future. To their list of questions, I would add 2 more: (1) should CME be a teambased activity rather than an individual activity?; and (2) what forms of CME offer best value for the sums spent on them? CME has become a multimillion dollar industry. If we are to continue to invest, surely we should have better data on cost-effectiveness, cost benefits or cost utility?

Competing interests: Mr. Walsh is Editor of BMJ Learning at the British Medical Association.

\section{References}

1. Ahmed K, Wang TT, Ashrafian H, Layer GT, Darzi A, Athanasiou T. The effectiveness of continuing medical education for specialist recertification. Can Urol Assoc J. 2013 Jul;7(7-8):266-272. http://dx.doi. org/10.5489/cuai.378

2. Walsh $\mathrm{K}$, Levin $\mathrm{H}$, Jaye P, Gazzard J. Cost analyses approaches in medical education: there are no simple solutions. Med Educ. 2013 0ct;47(10):962-8. http://dx.doi.org/10.1111/medu.12214

Correspondence: Dr. Kieran Walsh, BMJ Learning, BMA House, Tavistock Square, London WCIH 9JR; kmwalsh@bmigroup.com 